\title{
Transaxial Field of View
}

National Cancer Institute

\section{Source}

National Cancer Institute. Transaxial Field of View. NCl Thesaurus. Code C94995.

The diameter perpendicular to the body axis that can be imaged. 